of new theories about the relationship between humans and other animals: darwinism then, primatology now. She finds other parallels in the social composition of both movements and in the ideological linkages with other contemporary social movements, notably feminism.

The thesis is a bold but essentially simple one. Although sometimes diminished in effectiveness by too much repetition, much of what she writes is illuminating. But her supporting evidence is disappointing. Her account of the victorian movement covers relatively wellworked ground, and is based primarily on secondary sources. She occasionally displays a worryingly cavalier attitude to the fine details, especially of chronology, and greatly exaggerates the direct effect of experimental physiology and bacteriology on nineteeth-century clinical practice and the uniformity of beliefs among antivivisectionists.

The account of the modern movement is based mainly on interviews with nine representatives of the grass-roots groups campaigning against local universities, and on analysis of their pamphlets. This narrowly drawn sample has led her to concentrate unduly on one element in the modern movement and hence exaggerate its millennial character and its similarities with the earlier movement. In her search for the over-arching symbolic significance of the emergence of animal rights in Western technological societies (or rather in some of them), she has neglected the cultural specificity, complexity and heterogeneity of both the historical and the contemporary movements. Her rigid distinction between the humane movement and 'animal rights' activism, and her identification of modern antivivisection with apocalyptic views of the Earth's future, may have been appropriate for understanding the Californian movement in the early 1980s. But it provides only a partial understanding of, for example, modern British antivivisectionism.

Mary Ann Elston is in the Department of Com munity Medicine, University College London, 66-72 Gower Street, London WC1E 6EA, UK.

\section{Lost connections}

\section{Margaret A. Boden}

The Artificial Intelligence Debate: False Starts, Real Foundations. Edited by Stephen R. Graubard. MIT Press: 1988. Pp. 311. Pbk \$9.95, £8.95.

PEOPLE wanting an accessible entrée into exciting disputes within artificial intelligence should read this book (a reprint of a recent number of Daedalus). But the moralists among them will be saddened, and the literal-minded disappointed. For the promise explicit in the title is not honoured - and the sub-title gives the game away. If a debate is an argument in which each side has equal opportunity to make its case, this collection of essays is no debate: one side is enthusiastically favoured.

The "false starts" adumbrated in the sub-title, so most contributors tell us, were the early attempts of AI workers to model various aspects of intelligence by exploiting the logical-formalist properties of digital computers. The "real foundations", we are repeatedly informed, are the attempts - which have burgeoned in recent years - to ground a theory of intelligence in 'connectionist' computer models, in which massively parallel computations are carried out by myriad individual units analogous to neurons. But as the moralist and the literal-minded would surely have us admit, current connectionist models are 'toy' systems, relying on units which (though they share some important properties with nerve cells) are in many computationally signifi- first 'connectionist' work, on perceptrons, also prompted pioneering AI research in the formalist tradition (and had previously influenced von Neumann in his logical design of the digital computer). This fact alone should make one doubt whether there is such a deep paradigmatic divide between the "false starts" and the "real foundations" as most contributors suggest.

This point is made in the opening salvo of the confrontation, the chapter by Papert - the connectionists' demon king. Allowing that there is room within AI for insights drawn from connectionist as well as traditionalist theories, Papert nevertheless notes the small-scale nature of today's connectionist models, surmising that "the entire structure of recent connectionist theories [like the perceptrons he criticized so decisively in the 1960 s] might be built on quicksand".

The developing relations between neuroscience and AI are optimistically outlined by Schwarz, although Edelman's insistence that selection, not computation, is the key concept in understanding the brain sits uneasily with both branches of AI research. Cowan and Sharp sketch the history of the mathematical ideas underlying diverse forms of connectionist computation, from perceptrons to Boltzmann machines. Dreyfus heaps scorn on the conjectures investigated by 'traditional' AI over the past 30 years, greeting the recent research on parallel distributed processing with a (largely unfounded) I told you so!. Sokolowski gives a useful conceptual analysis of the term 'artificial', pointing out that, even if natural and artificial intelligence differ significantly, the study of the latter variety would be part of science (as opposed to technology) if it helped us to understand - whether by emulation or contrast our natural capacities. Poggio describes advances in the computational theory of vision, based on broadly connectionist ideas. Further essays are contributed by noted workers in and commentators on the field: Waltz, Hillis, McCarthy, Turkle, McCorduck, Putnam and Dennett.

As a readable account of some of the achievements and many of the hopes of current connectionism, this collection is both useful and enjoyable. But it should have dealt more seriously with the shortcomings of today's connectionist systems, some of which arguably call for a sequentialist, even a formalist, theory of certain aspects of mental processing. Popper's advice on how to deal with one's intellectual opponents in the most constructive and the most telling - way was ignored: state their case (or allow them to state it) as well as possible, before mounting your attack. Only then can you be sure that the beast is rightly slain.

Margaret A. Boden is in the School of Cognitive and Computing Sciences, University of Sussex, Brighton $B N 19 Q N, U K$ 